Adoção Tardia: Altruísmo, Maturidade e Estabilidade Emocional

\title{
Adoção Tardia: Altruísmo, Maturidade e Estabilidade Emocional
}

\author{
Surama Gusmão Ebrabim ${ }^{12}$ \\ Universidade Federal da Paraíba
}

\begin{abstract}
Resumo
A pesquisa teve por objetivo executar um estudo acerca das adoções tardias, comparando pais que realizaram adoções de crianças maiores de dois anos com pais que efetuaram adoções de bebês. Os principais elementos abordados foram: estado civil; idade; escolaridade; renda; presença de filhos biológicos; e motivações para a adoção. Investigaram-se também o altruísmo, a maturidade e a estabilidade emocional dos adotantes. A amostra consistiu de 27 adotantes tardios e 55 adotantes convencionais, participantes ou não de Grupos de Apoio à Adoção. O instrumento utilizado constou de um questionário sobre adoção; de questões sobre maturidade e estabilidade emocional; e de uma escala de altruísmo. Os resultados indicaram distinções referentes aos aspectos destacados. Os adotantes tardios apresentaram um nível sócio-econômico superior, um estado civil mais diferenciado, uma maior presença de filhos biológicos, e uma maturidade e estabilidade mais elevada. Quanto às motivações e ao altruísmo, apareceram diferenças significativas entre os dois grupos.

Palavras-chave: Adoção; abandono; altruísmo; maturidade e estabilidade emocional.
\end{abstract}

\section{Late Adoption: Altruism, Maturity, and Emotional Stability}

\begin{abstract}
This research work aimed at carring out a study on late adoptions, comparing parents who adopted children over two years old with those who adopted babies. The main elements focused on were: civil status; age; education; level of income; presence of biological children; and motivations for the adoption. Altruism, maturity, and emotional stability of the adopters were also investigated. The sample consisted of 27 late adopters and 55 conventional adopters, regardless of their participation in Groups of Support for Adoption. The instrument used consisted of a questionnaire about adoption; questions about maturity and emotional stability; and of a scale of altruism. The results indicated distinctions to the emphasized aspects. The late adopters, compared to the conventional ones, featured a higher social and economic level, differences in their marital status, a higher proportion of biological children, and a higher maturity and stability. Regarding both motivations and altruism, the two groups presented significant differences.

Keywords: Adoption; abandon; altruism; maturity, and emotional stability.
\end{abstract}

A adoção é, em si, um tema bastante complexo, sendo a adoção tardia, de acordo com algumas pesquisas (Weber \& Cornélio, 1995; Weber \& Gagno, 1995), revestida de muito preconceito. Como afirmam Vargas e Weber (1996), a maior parte das publicações brasileiras - que são bem poucas - descrevem casos clínicos e psiquiátricos,

\footnotetext{
${ }^{1}$ Endereço para correspondência: Rua Norberto de Castro Nogueira, 505/302, Bessa, João Pessoa, PB, 58036-080. Fone: (83) 2463972. E-mail: Ebrahim@netwaybbs.com.br

${ }^{2}$ Este trabalho foi derivado da Dissertação de Mestrado da autora: Adoção Tardia - Altruísmo, Maturidade e Estabilidade Emocional, Universidade Federal da Paraíba. Versão parcial foi apresentada no IV Encontro Nacional de Associações e Grupos de Apoio à Adoção e II Encontro Norte/ Nordeste sobre Adoção, Natal, 1999.
}

criando uma clara distorção, que leva à associação da adoção com problemas e fracassos.

Entretanto, especialmente nos últimos anos, com a maior divulgação do tema, através da difusão dos Grupos de Estudos e de Apoio à Adoção, e o fortalecimento do movimento voltado para a disseminação do mesmo, novas publicações, em grande parte através dos boletins informativos destes mesmos grupos (Informativo GEAD, GIAARO, GEAF, entre outros), começaram a efetivar-se, procurando desmistificar os conceitos errôneos existentes.

A finalidade precípua, na atualidade, é a de difundir uma "cultura da adoção", para proporcionar um lar para crianças que não o têm, sem valorizar demasiadamente condições de saúde, cor, gênero, raça, idade. Porém, a adoção no Brasil, ainda é comumente vista como solução 
para a infertilidade, constituindo uma das razões para a procura maciça de bebês.

Em geral, somente as crianças de até três anos conseguem colocação em famílias brasileiras. A partir dessa idade a adoção torna-se mais difícil. Grande parte das crianças, consideradas mais velhas, ou é adotada por estrangeiros ou permanece em instituições (Weber \& Kossobudzky, 1996; Weber \& Mafessoni, 1996).

Os conceitos dos adotantes quanto à adoção de crianças mais velhas, e que surgem como forma de justificar a preferência por bebês, relacionam-se, fundamentalmente, com a dificuldade na educação. Segundo as famílias adotivas, dificilmente uma criança adotada tardiamente aceitaria os padrões estabelecidos pelos pais, pois estariam com sua formação social iniciada. As pessoas, portanto, adotariam bebês para obterem uma melhor adaptação entre pais e filhos e uma adequada socialização, onde as crianças fossem capazes de atender aos anseios da família (Weber, 1996).

As pesquisas revelam (Weber, Gagno, Cornélio \& Silva,1994; Weber \& Cornélio, 1995; Weber \& Gagno, 1995) que a maior parte da população apresenta preconceitos quanto à adoção tardia, como: a) o medo de adotar crianças mais velhas pela dificuldade na educação; b) o receio de adotar crianças institucionalizadas pelos maus hábitos que trariam; c) as crianças que não sabem que são adotivas têm menos problemas, por isso deve-se adotar bebês e esconder deles a verdade, imitando uma família biológica. É usual, portanto, que sejam confundidas a aceitação e a inserção completa da criança na família, com o desejo e a tentativa de apagar suas origens (Motta, 1995). A adoção, desta maneira, termina por não ser um processo simples, especialmente aquela relativa a crianças mais velhas. Mas, como questionam Weber e Kossobudzki (1996, p. 124), "será que a sociedade não é capaz de mudar, de preparar as pessoas e proporcionar de fato o encontro de pais para todas as crianças?". A importância do presente estudo baseia-se, assim, no fato de que grande quantidade de crianças maiores continua sem família, enquanto os cadastros de candidatos à adoção pleiteiam bebês. As crianças maiores ficam à espera de pais, e os pais à espera de bebês. São relativamente desconhecidas em pesquisas, a extensão e a variabilidade do fator adoção tardia e dos elementos motivadores de tal tipo de adoção. O objetivo geral deste trabalho é, então, realizar um estudo empírico acerca da adoção tardia. Mais especificamente, pretendese verificar se existem diferenças e/ou semelhanças entre os grupos que realizam adoções convencionais (bebês) e os grupos que realizam adoções tardias (maiores de dois anos). Na inexistência de estudos similares ${ }^{3}$, tanto no Brasil como no exterior, que comparem adotantes tardios e convencionais, são levantadas hipóteses quanto à diferença entre os dois grupos, acreditando-se que ocorrem, basicamente, ao nível das características de personalidade. Supõe-se que as pessoas que adotam crianças maiores são mais altruístas, maduras e estáveis emocionalmente.

Segundo Serra e Zacares (1991), a maturidade psicológica vem como conseqüência de um processo que se estrutura durante o ciclo de vida do indivíduo, na interação entre traços biológicos, psicológicos e sociais, e na progressão de um ótimo equilíbrio entre o conceito de si e as mudanças de papel inerentes à vida. As características desenvolvimentais específicas da maturidade emocional incluem o desenvolvimento do afeto, da perspectiva de tempo, da autonomia, independência, responsabilidade, e o reconhecimento de coerências e dissonâncias entre as emoções e os comportamentos.

$\mathrm{O}$ indivíduo emocionalmente sadio é aquele que consegue ter controle emocional sem suprimir a emocionalidade, experimentando impulsos carregados de emoção, mas com apropriado equilíbrio entre a sensação e a expressão (Hilgard, Atkinson \& Atkinson, 1971, citados por Pisani, Bisi, Rizzon \& Nicoletto, 1989). A estabilidade emocional implica na capacidade de tolerar as frustrações decorrentes de condições insatisfatórias, sem esquivar-se destas, vendo-as e enfrentando-as de forma realista, com constância e equilíbrio do comportamento (Andrade \& Alves, 1993).

Francis (1997) coloca que os indivíduos mais estáveis emocionalmente são aqueles que mantêm um bom conceito próprio, o que parece indicar uma relação entre elevada maturidade, estabilidade emocional e uma visão pessoal positiva. Similarmente, os dados de Perez San Gregorio, Roldan, Cabezas e Roldan (1993) e os de Jha (1995) demonstram uma ligação entre estabilidade emocional, auto-estima e altruísmo.

O altruísmo é classificado por Korsgaard, Meglino e Lester (1996) como um comportamento designado a atender às necessidades de outros, envolvendo escolhas em que os indivíduos colocam menos valor em resultados pessoais e demonstram pouca disposição em se ocupar de cálculos racionais que abrangem custos e benefícios.

\footnotetext{
${ }^{3}$ As publicações mais freqüentes sobre adoção são internacionais e têm versado sobre a comparação de adotivos e não-adotivos, adoções de crianças com necessidades especiais e estudos teóricos sobre o tema, demonstrando interesse no esclarecimento das características das crianças adotadas e na necessidade de serviços de aconselhamento às famílias (Vargas \& Weber, 1996).
} 
Mulligan (1996) enfatiza que a composição familiar, o tamanho da família, a ordem de nascimento e algumas variáveis da infância, trazem implicações na formação do altruísmo e na transmissão de sentimentos de igualdade ou desigualdade entre as pessoas. Ma e Leung (1995) julgam que a educação informal oferecida pela família, além da educação formal dos programas sociais, favorece orientações altruísticas. Os resultados do estudo mostram uma relação positiva entre ambiente familiar e altruísmo. Uma forte orientação altruística está substancialmente associada com um ambiente familiar coeso e harmonioso, onde há ênfase constante em atividades intelectuais e culturais. Sob estes pontos de vista, as pessoas que realizam adoções tardias talvez ajam seguindo uma orientação altruística, facilitada pela estabilidade e maturidade emocional, onde as situações familiares, as experiências de vida e a idade podem ser significativas, influenciando o modo como os indivíduos respondem às necessidades dos outros. Ademais, os adotantes tardios podem, na sua maioria, ser casais com filhos, que já vivenciaram a experiência de criar uma criança, não tendo mais a necessidade ou disponibilidade de começar com um bebê. Ou pessoas sozinhas, como solteiros, divorciados e viúvos, que não têm tempo e condições de cuidar de um recém-nascido, mas querem constituir uma família. Ao passo que, os adotantes convencionais são casados e sem filhos biológicos. Pretende-se ainda verificar diferenças sócio-econômicas entre os grupos. Os estudos de Weber (1995) indicam que as pessoas de classes sociais baixas fazem menor número de exigências em relação à criança, adotando, com mais freqüência, crianças maiores. Espera-se que os dados coletados, em conformidade com estas hipóteses, possam contribuir com maiores esclarecimentos sobre a adoção tardia, possibilitando a estruturação de planos de intervenção voltados para conscientizar a população e reduzir os preconceitos sobre o tema, ajudando crianças mais velhas a encontrar famílias que as acolham.

\section{Participantes}

\section{Método}

O conjunto de participantes foi composto por adotantes que realizaram adoções tardias (27) e adoções convencionais (55), participantes ou não de Associações e Grupos de Apoio à Adoção, perfazendo um total de 82 sujeitos. A amostra foi composta por casais, pessoas solteiras, viúvas e separadas/divorciadas. É importante considerar que apenas os instrumentos respondidos pelas mães adotivas foram considerados na análise dos dados, pois somente seis pais adotivos enviaram resposta ao instrumento.

\section{Instrumentos}

O instrumento de pesquisa constou de um questionário sobre adoção, com questões abertas e fechadas. Além disso, foi constituído por questões fechadas sobre maturidade e estabilidade emocional, retiradas das formas A e B do Questionário de Dezesseis Fatores de Personalidade (16PF) de Cattell (traduzido e adaptado por Andrade \& Alves, 1993) e de uma escala de altruísmo, construída e validada pela autora. O questionário foi concluído com questões relativas a dados pessoais, pertinentes ao tema da pesquisa.

Para avaliar a maturidade e a estabilidade psicológica dos pais adotivos escolheu-se o Fator C do Questionário $16 \mathrm{PF}$, por ser este o único instrumento de medida encontrado, através de fontes primárias (artigos, livros, teses) e fontes secundárias de informação (sistemas informatizados de identificação bibliográfica), que abordava, simultaneamente, os dois fatores. Afora isto, tinha a facilidade de ser validado no Brasil, pois seria inviável realizar a elaboração e a validação de dois instrumentos, quando a escala de altruísmo já estava sendo construída, para posterior validação.

A escala de altruísmo foi elaborada com base na subescala de altruísmo da Escala de Filosofias da Natureza Humana de Wrighstman (1964), e complementada com questões formuladas sob a teoria. A escala ficou composta por cinco itens, sendo os três primeiros baseados na adaptação da escala de Wrigsthman, e os dois últimos, na temática acerca do altruísmo. A escala foi aplicada na população em geral, com a amostra, para tanto, constituída por 84 sujeitos, sendo 48 do sexo feminino $(57,1 \%)$, e 36 do masculino (42,9\%). Para determinar a validade de construto da referida escala, utilizou-se a Análise Fatorial para a extração dos componentes principais, com a finalidade de verificar a factorabilidade das matrizes de correlação. Como resultado, foram mantidos os cinco itens, por apresentarem correlações acima de 0,25. Em seguida, realizou-se uma segunda análise fatorial, com o método PAF (Principal Axis Factoring), onde se constatou a existência de um único fator com eigenvalue de 1,46, explicando $29 \%$ da variância, e com coeficiente de precisão (alfa de Cronbach) de 0,64. Os itens apresentaram cargas fatoriais acima de 0,30, com a medida do KMO (Kaiser-Meyer-Olkin) total de 0,69. A partir da conclusão da avaliação dos dados da escala, em relação à população em geral, os parâmetros puderam ser transpostos, tanto em termos de formulação dos itens, como da forma de analisá-los, para a aplicação às amostras dos adotantes (tardios e convencionais). 


\section{Procedimentos}

Os instrumentos de pesquisa foram entregues pessoalmente, ou remetidos via correio, aos coordenadores dos grupos e associações de apoio à adoção, e a profissionais (assistentes sociais, professores, psicólogos, entre outros) que serviam de intermediários entre os adotantes e a pesquisadora, em oito estados brasileiros. Os envelopes para resposta foram enviados selados e endereçados, para facilitar o retorno e ocorrerem menos perdas, juntamente como uma carta explicativa sobre os objetivos do estudo. Mas, como era esperado, apenas 38\% dos instrumentos postos em aplicação retornaram.

\section{Resultados}

No estudo relacional das variáveis do questionário, tomou-se como parâmetro o teste de qui-quadrado, e na ausência de significância dos dados, avaliou-se a distribuição das freqüências. $\mathrm{Na}$ análise do altruísmo e da maturidade e estabilidade emocional, utilizou-se a razão $t$ e a prova de Mann-Whitney, que possibilitaram a comparação entre as duas amostras citadas. As características das amostras dos adotantes convencionais e dos adotantes tardios apresentam-se distintas em alguns aspectos, como o estado civil e a idade (Tabelas 1, 2 e 3).

É interessante observar que entre as mulheres que realizaram adoções tardias há uma maior variância nas
Apesar da diferença entre as médias de idade dos adotantes tardios e convencionais ser pequena, o primeiro grupo apresenta uma idade média mais elevada. Quanto ao nível de escolaridade, percebe-se pelos resultados das Tabelas 4 e 5, que as mulheres que realizaram adoções tardias possuem um nível de escolaridade mais elevado do que os homens, entre os dois grupos de adotantes.

Vê-se pelas Tabelas 4 e 5, que $52 \%$ das mães adotivas de bebês e $74,1 \%$ das mães que adotaram crianças maiores têm nível superior completo, e entre os pais, $54,3 \%$ dos pais adotivos convencionais e $50 \%$ dos pais adotivos tardios, têm este mesmo nível de formação. Em relação

Tabela 4. Percentagens e Freqüência Relativa à Escolaridade Materna

adotantes $\operatorname{tardias} \%$ adotantes convencionais $\%$

$\begin{array}{lrr}\text { sem escolaridade } & 3,7(1) & 0 \\ \text { primário (1a a } \text { 4 }^{\mathrm{a}} \text { série) } & 7,4(2) & 2(1) \\ \text { primário (5a a } 8^{\mathrm{a}} \text { série) } & 3,7(1) & 8(4) \\ \text { secundário } & 7,4(2) & 24(12) \\ \text { superior incompleto } & 3,7(1) & 14(7) \\ \text { superior completo } & 74,1(20) & 52(26)\end{array}$

* O total corresponde a $n=77$, porque das adotantes convencionais pesquisadas $(n=55)$, somente 50 informaram o nível de escolaridade.

Tabela 1. Freqüências e Percentagens Relativas ao Estado Civil Materno

\begin{tabular}{lcccc}
\hline & solteira & casada & separada/divorciada & viúva \\
\hline adotantes tardias & $25,9 \%(7)$ & $66,7 \%(18)$ & $3,7 \%(1)$ & $3,7 \%(1)$ \\
adotantes convencionais & $6,1 \%(3)$ & $91,9 \%(45)$ & $2 \% \quad(1)$ & - \\
\hline
\end{tabular}

* O total corresponde a $n=76$, porque uma parcela das adotantes convencionais $(n=6)$ não especificou o estado civil.

respostas. Entre as mães que adotaram bebês, $91,9 \%$ são casadas, enquanto apenas $66,7 \%$ das mães que adotaram crianças maiores o são. A média de idade das mães adotivas de bebês é de 35 anos e a dos pais, de 38 anos. Para as mães de crianças maiores, a média de idade é de 38 anos, e entre os pais, de 42 anos (Tabelas 2 e 3 )

Tabela 2. Médias e Desvios-Padrão das Idades Maternas

\begin{tabular}{lcc}
\hline & médias & \multicolumn{1}{c}{} \\
\hline adotantes tardias & 37,78 & 8,25 \\
adotantes convencionais & 35,34 & 7,05 \\
\hline
\end{tabular}

Tabela 3. Médias e Desvios-Padrão das Idades Paternas

\begin{tabular}{lcc}
\hline & médias & $d p$ \\
\hline adotantes tardios & 42,06 & 11,24 \\
adotantes convencionais & 38,26 & 7,65 \\
\hline
\end{tabular}

à renda familiar, os dados encontrados podem ser visualizados na Tabela 6 .

Tabela 5. Percentagens e Freqüências Relativas à Escolaridade Paterna

\begin{tabular}{|c|c|c|}
\hline \multicolumn{3}{|c|}{ adotantes tardios $\%$ adotantes convencionais $\%$} \\
\hline primário (1ํa a $4^{\underline{a}}$ série $)$ & 0 & $2,2(1)$ \\
\hline primário ( $5^{\underline{a}}$ a $8^{\underline{a}}$ série) & $11,1(2)$ & $6,5(3)$ \\
\hline secundário & $22,2(4)$ & $26,1(12)$ \\
\hline superior incompleto & $16,7(3)$ & $10,9(5)$ \\
\hline superior completo & $50 \quad(9)$ & $54,3(24)$ \\
\hline
\end{tabular}

* O total corresponde a $n=64$ porque indica o nível de escolaridade dos pais adotivos, o que só pode ser informado no caso das adoções efetuadas por casais (adotantes tardios: $n=18$; adotantes convencionais: $n=45$ ). Nenhum adotante que tenha realizado adoções quando solteiro, viúvo ou separado/divorciado participou do estudo. 
A renda salarial familiar dos adotantes convencionais fica acima de 20 salários mínimos para 36,7\% da amostra, e entre os adotantes tardios, $40,7 \%$ recebem mais de 20 salários. Desta forma, o grupo de adotantes tardios demonstra uma condição econômica melhor do que a

Tabela 6. Percentagens e Freqüências Relativas à Renda Salarial Familiar $(n=76)$

\begin{tabular}{lcc}
\hline & adotantes tardios & adotantes convencionais \\
\hline até 1 salário & $3,7(1)$ & $3,7(1)$ \\
até 3 salários & 0 & $6,1(3)$ \\
até 5 salários & 0 & $4,1(2)$ \\
até 8 salários & $7,4(2)$ & 2 \\
até 12 salários & $7,4(2)$ & $14,3(7)$ \\
até 15 salários & $14,9(4)$ & $16,4(8)$ \\
até 20 salários & $25,9(7)$ & $18,4(9)$ \\
acima de 20 salários & $40,7(11)$ & $36,7(18)$ \\
\hline
\end{tabular}

do grupo de adotantes convencionais, o que revela uma contradição na direção dos resultados previstos. $\mathrm{Na}$ Tabela 7 é possível verificar a presença ou ausência de filhos biológicos nas famílias adotivas.

A Tabela 7 demonstra que $63 \%$ das famílias com adoções tardias são compostas também por filhos

Tabela 7. Percentagens e Freqüências da Presença/ Ausência de Filhos Biológicos nas Famílias Adotivas

\begin{tabular}{lcc}
\hline & presença & ausência \\
\hline adotantes tardios & $63(17)$ & $37(10)$ \\
adotantes convencionais & $49,1(27)$ & $50,9(28)$ \\
\hline
\end{tabular}

biológicos, o que ocorre em 49,1\% das famílias com adoções de bebês. Quanto à motivação para a adoção, a Tabela 8 abaixo lista os elementos mais citados como motivadores para a realização da adoção, nos grupos dos adotantes tardios e dos convencionais.

Os resultados relativos aos motivos elencados pelos adotantes para efetuar as adoções revelam que os adotantes tardios adotam mais por se sensibilizarem com a situação de abandono das crianças ( $51,9 \%$ ), enquanto que as pessoas que adotam bebês o fazem, na maior parte das vezes, por não ter os próprios filhos (46,3\%). Observa-se uma diferença significativa quanto à situação de abandono $\left(X^{2}=5,349 ; g l=1 ; p<0,05\right)$ e a ausência de filhos biológicos $\left(X^{2}=5,956 ; g l=1 ; p<0,05\right)$ favorecendo as adoções, na comparação entre os dois grupos.

Em relação à questão da maturidade e estabilidade emocional, o que pôde ser percebido, foi uma média maior entre os adotantes tardios em comparação com os adotantes convencionais. A média encontrada entre os adotantes tardios foi de $m=13,65(d p=3,39)$ e entre os adotantes convencionais, de $m=12,33(d p=3,50)$, conforme pode ser visualizado na Tabela 9 .

Tabela 9. Médias e Desvios-Padrão da Maturidade e Estabilidade Emocional entre os Adotantes Tardios e Convencionais

\begin{tabular}{lcc}
\hline & médias & desvios-padrão \\
\hline adotantes tardios & 13,65 & 3,39 \\
adotantes convencionais & 12,33 & 3,50 \\
\hline & $Z=-1,771 ;$ & $p<0,08$
\end{tabular}

Estes resultados, ao nível de $8 \%$, indicam uma tendência a diferenças significativas entre os dois grupos, com os adotantes tardios apresentando índices mais elevados de maturidade e estabilidade emocional.

A respeito do altruísmo, surgiu uma diferença significativa entre as duas amostras, com os adotantes tardios atingindo um escore médio mais elevado que os adotantes convencionais $(m=21,89 ; d p=2,32 \mathrm{e} m=20,61$; $d p=2,71$, respectivamente).

Tabela 8. Percentagens e Freqüências dos Motivos para a Adoção

\begin{tabular}{lccc}
\hline & adotantes tardios & adotantes convencionais \\
\hline não ter os próprios filhos & $18,5(5)$ & $46,3(25)$ \\
caridade, pena, amor ao próximo & $22,2(6)$ & $1,9(1)$ \\
para dar um irmão a um filho único & $11,1(3)$ & 13 & $(7)$ \\
a situação de abandono das crianças & $51,9(14)$ & $25,9(14)$ \\
para construir uma família, sendo solteiro & $14,8(4)$ & $1,9(1)$ \\
por achar a criança na porta de casa/ rua & 0 & $16,7(9)$ \\
por valores religiosos & $22,2(6)$ & $7,4(4)$ \\
para se sentir mais completo & $14,8(4)$ & $27,8(15)$ \\
por desejar mais um filho e não poder gerar & $7,4(2)$ & $11,1(6)$ \\
\hline
\end{tabular}

* Respostas múltiplas. 
Tabela 10. Médias e Desvios-Padrão do Altruísmo entre Adotantes Tardios e Convencionais

\begin{tabular}{lcc}
\hline & Médias & Desvios-padrão \\
\hline adotantes tardios & 21,89 & 2,32 \\
adotantes convencionais & 20,61 & 2,71 \\
\hline \multicolumn{2}{c}{$t=-2,090 ; g l=79 ; p<0,04$}
\end{tabular}

\section{Discussão}

Inicialmente, seria importante recordar que se estabeleceu, como uma das hipóteses, a partir de pesquisas de Weber $(1995,1996,1997)$, que as pessoas de nível sócio-econômico baixo estariam mais abertas à adoção, adotando freqüentemente crianças maiores. Entretanto estes não foram os resultados encontrados, na medida que, quanto à escolaridade, $74,1 \%$ das mães e $50 \%$ dos pais que realizaram adoções de crianças maiores, têm nível superior completo e $40,7 \%$ possuem uma renda salarial familiar acima de 20 salários, ao passo que entre os adotantes de bebês, $52 \%$ das mães e $54,3 \%$ dos pais desfrutam de nível superior completo e $36,7 \%$ apresentam uma renda salarial acima de 20 salários. Logo, o nível sócio-econômico dos adotantes tardios não corrobora o previsto, tendo os adotantes convencionais uma condição social e financeira inferior, ao menos na amostra estudada. Em relação às outras hipóteses estabelecidas, ao contrário, os dados colhidos mantêm-se na direção esperada, pois, como se supunha, os adotantes tardios compõem uma amostra mais ampla, sendo casados $(66,7 \%)$, solteiros $(25,9 \%)$, viúvos $(3,7 \%)$ ou divorciados $(3,7 \%)$, em sua maioria com filhos biológicos (63\%), o que se opõe aos adotantes convencionais, casados na sua quase totalidade $(91,9 \%$ ) e sem filhos biológicos $(50,9 \%)$. Como afirmam Ferreyra (1993) e Prowler (1990), muitas pessoas sem filhos ou casais com filhos, estão se dispondo às adoções tardias, inter-raciais e de crianças com necessidades especiais, tendo havido um aumento considerável de adotantes solteiros que se sentem com tempo e afeto suficiente para acolherem uma criança maior. Deste modo, o estado civil e a presença ou ausência de filhos biológicos relaciona-se com os dados encontrados em termos das motivações para a adoção. O fato da maior parte dos adotantes de bebês ser casada e não ter filhos fundamenta os principais motivos descritos por estes para a realização das adoções, como: "não ter os próprios filhos" e "para se sentir mais completo". Entre os adotantes tardios, onde há maior presença de filhos biológicos e a situação civil é mais diferenciada, aparecem como fatores explicativos: "a situação de abandono das crianças; caridade, pena, amor ao próximo; e valores religiosos".
A respeito do altruísmo, este emerge como um componente a influenciar as escolhas dos adotantes, pois, como presumido, os adotantes tardios mostram-se mais altruístas do que os adotantes convencionais, tendo havido uma diferença significativa entre os dois grupos. Como mencionam Shapiro e Gabbard (1994) e Korsgaard, Meglino e Lester (1996), o altruísmo é um comportamento que não se limita a ganhos ou interesses próprios. Um ato é definido como altruístico a partir da motivação do sujeito, que coloca pouco valor nos resultados pessoais e nos custos de suas escolhas.

Isto explica a diferença significativa encontrada em relação às motivações, quanto à situação de abandono, nas adoções tardias e a ausência de filhos biológicos, nas adoções convencionais, favorecendo a tomada de decisão dos adotantes. O altruísmo, mais elevado entre os adotantes tardios, traz uma maior justificativa para a motivação apresentada por estes, de uma preocupação em atender às necessidades do outro como mobilizadora das adoções.

A questão da maturidade pode ser um outro fator importante na determinação da decisão dos indivíduos adotarem bebês ou crianças mais velhas. A maturidade e a estabilidade emocional compõem, como se imaginava, um elemento de diferenciação entre os dois grupos, com os adotantes tardios mostrando-se mais maduros e estáveis emocionalmente do que os adotantes convencionais. Isto pode ser determinado, em parte, pela idade dos adotantes, já que os adotantes tardios apresentam uma idade média mais elevada do que os adotantes convencionais e a literatura indica haver um progresso similar da idade com a maturidade (Lawton, Kleban, Rajagopal \& Dean, 1992; Shaughnessy \& Evans, 1987) e uma relação entre idade, estabilidade e maturidade emocional, e pensamento altruístico (Eisenberg, 1996; Jha, 1995; Perez San Gregorio, Roldan, Cabezas \& Roldan, 1993).

\section{Conclusão}

Como exposto no princípio deste trabalho, há uma escassez de pesquisas relacionadas à questão da adoção, especialmente no Brasil. A maior parte dos estudos (Eldred, 1976; Partridge, 1991; Pinderhughes, 1996; Verhulst \& Verhulst, 1995; Wadsworth, De Fries \& Fulker, 1993) são provenientes dos Estados Unidos, sendo realizados mais com adotados, ou estabelecendo comparações entre grupos de adotivos e não adotivos, do que dedicados aos adotantes. O estudo tem seu valor pela carência de trabalhos que examinem as experiências e motivações próprias dos adotantes tardios, permitindo 
compreender melhor quais são os elementos favorecedores da adoção de crianças maiores para poder trabalhá-los em prol da concretização de novas adoções deste tipo. Desta maneira, a proposta primeira da pesquisa foi cumprida, com o levantamento das principais diferenças e semelhanças encontradas entre adotantes tardios e convencionais, e como estas atuam nas escolhas dos adotantes. Conclui-se que as motivações para as adoções tardias são beneficiadas pelas características de personalidade dos adotantes, o que não impede, entretanto, que outros, nem tão maduros nem tão altruístas adotem crianças maiores. A intenção não é de excluir aqueles que não possuem estas mesmas características, achando que somente eles seriam capazes de realizar uma adoção tardia com sucesso, mas de procurar formas de impulsionar novas adoções, mesmo com pessoas que dispõem de caracteres diferenciados. Por outro lado, como acreditam Frydman, Ledruc, Hofmans e Molinier (1995) e Stark (1996), através de programas multidimensionais de educação social, pode-se desenvolver e/ou aumentar comportamentos pró-sociais na população. Esta é uma possibilidade que se abre para todos os que estão interessados na questão do abandono e institucionalização de crianças e adolescentes.

\section{Referências}

Andrade, E. M. \& Alves, D. G. (1993). 16PF Manual abreviado-normas brasileiras, Rio de Janeiro: Capra.

Eisenberg, N. (1996). Tenns' altruism grows like they do-in spurts. APA Monitor. Washington: American Psychological Association.

Eldred, C. (1976). Some aspects of adoption in selected samples of adult adoptees. American Journal Orthopsychiatry, 46, 279-290.

Ferreyra, M. C. (1993). A adoção de crianças maiores. Boletim A Adoção em Terre des Hommes, 51(5), 1-6.

Francis, L. J. (1997). The relationship between Rosenberg's construct of self esteem and Eysenck's two-dimensional model of personality. Personality and Individual Differences, 22(1), 139.

Frydman, M. , Ledruc, L. , Hofmans, V. \& Molinier, C. (1995). The development of altruistic attitudes. Enfance, 1, 89-100.

Jha, P. K. (1995). Personality correlates of machiavellians. Indian Journal of Psychometry and Education, 26(2), 65-70.

Korsgaard, M. A., Meglino, B. M. \& Lester, S. W. (1996). The effect of other-oriented values on decision making: A test of propositions of a theory of concern for others in organizations. Organizational Behavior and Human Decision Processes, 68(3), 234-245.

Lawton, M. P. , Kleban, M. H. , Rajagopal, D. \& Dean, J. (1992). Dimensions of affective experience in three age groups. Psychology and Aging, 7(2), 171-184.

Ma, H. K. \& Leung, M. C. (1995). The relation of altruistic orientation to family social environment in chinese children. Psychologia an International Journal of Psychology in the Orient, 38(2), 109-115.

Motta, M. A. P. (1995). Adoção: Uma verdade a ocultar? Revista Literária de Direito, 7(2), 23.

Mulligan, C. B. (1996). Parental Priorities and Economic Inequality. Chicago: University of Chicago Press.

Partridge, P. C. (1991). The particular challenges of being adopted. Smith College Studies in Social Work, 61(2), 197-208.
Perez San Gregorio, M. A., Roldan, J. M. D., Cabezas, F. M. \& Roldan, A. N. (1993). Factores sociales y psicologicos que influyen en la donación de órganos. Psychotema, 5(2), 241-253.

Pinderhughes, E. E. (1996). Toward understanding family readjustment following older child adoptions: The interplay between theory generation and empirical research. Children and Youth Services Review, 18(1-2), 115-138.

Pisani, E. M., Bisi, G. P., Rizzon, L. A. \& Nicoletto, U. (1989). Psicologia Geral. Porto Alegre: Vozes.

Prowler, M. (1990). Single parent adoption: What you need to know. Washington, DC: National Adoption Center.

Serra, E. \& Zacares, J. J. (1991). A que llamamos madurez. Revista de Psicologia e de la Educacion, 3(8), 1-18.

Shapiro, Y. \& Gabbard, G.O. (1994). A reconsideration of altruism from an evolutionary and psychodynamic perspective. Ethics and Behavior, $4(1), 23-42$.

Shaughnessy, M. F. \& Evans, R. (1987). The meaningful personality. International Forum for Logotherapy, 10(1), 46-49.

Stark, O .(1996). On the evolution of altruism. Noruega: University of Oslo.

Vargas, M. M. \& Weber, L. N. D. (1996). Um estudo das publicações científicas internacionais sobre adoção. Em Sociedade Brasileira de Psicologia (Org.), Resumos de comunicacoões científicas, XXVI Reunião Anual de Psicologia (p. 118). Ribeirão Preto: SBP.

Verhulst, F. C. \& Versluis-den Bieman, H. J. M. (1995). Developmental course of problem behaviors in adolescent adoptees. Journal American Academy of Child and Adolescent Psychiatry, 34(2), 151-159.

Wadsworth, S. J., De Fries, J. C. \& Fulker, D. W. (1993). Cognitive abilities of children at 7 and 12 years of age in the Colorado Adoption Project. Journal of Learning Disabilities, 26(9), 611-615.

Weber, L. N. D. (1995). Família e adoção. Em Congresso Latino-Americano de Psiquiatria (Org.), Caderno de resumos, X Congresso LatinoAmericano de Psiquiatria da Infancia e da Adolescência (p. 72). Curitiba, Paraná

Weber, L. N. D. (1996). A Pesquisa sobre adoção como um fator preventivo. Em Sociedade Brasileira de Psicologia (Org.), Resumos de comunicações cientificas, XXVI Reunião Anual de Psicologia (p. 18). Ribeirão Preto: SBP.

Weber, L. N. D. (1997). O lado de dentro: Sentimentos, desejos e expectativas de crianças institucionalizadas. Comunicação apresentada no II Encontro Nacional de Associações e Grupos de Apoio à Adoção. Itapetininga, São Paulo.

Weber, L. N. D \& Cornélio, S. A. (1995). Filhos adotivos: Amores ou dissabores? Em Sociedade Brasileira para o Progresso da Ciência (Org.), Caderno de Resumos, 46 Reunião Anual para o Progresso da Ciência (p. 873). Vitória.

Weber, L. N. D. \& Gagno, A. P. (1995). Onde estão os vínculos afetivos das crianças institucionalizadas? Em Congresso Latino-Americano de Psiquiatria da Infância e da Adolescência (Org.), Caderno de Resumos, $X$ Congresso de Psiquiatria (p. 25). Curitiba.

Weber, L. N. D., Gagno, A. P., Cornélio, S. A. \& Silva, M. L. (1994). Adoção: Pré-conceitos, conceitos e pós-conceitos. Em Sociedade Brasileira para o Progresso da Ciência (Org.), Caderno de Resumos, 46 Reunião Anual para o Progresso da Ciência (p. 854). Vitória: SBPC.

Weber, L. N. D. \& Kossobudzki, L. H. M. (1996). Filhos da solidão: Institucionalização, abandono e adoção. Curitiba: Governo do Estado do Paraná.

Weber, L. N. D. \& Mafessoni, C. S. E. S. R. (1996). Um estudo comparativo das adoções nacionais e internacionais realizadas no Juizado da Infância e da Juventude de Curitiba. Em Sociedade Brasileira de Psicologia (Org.), Resumos de Comunicaşões Científicas, XXVI Reunião Anual de Psicologia (p. 119). São Paulo: SBP.

Wrighstman, L. S. (1964). Measurement of philosophies of human nature. Psychological Reports, 14, 743-751. 
Sobre a autora:

Surama Gusmão Ebrahim é psicóloga, Mestre pela Universidade Federal da Paraíba. 